\title{
Emergency Department Visits due to the Bleeding Complication of Warfarin
}

\author{
D Bahar Gülcay Çat,, (1) Umut Yücel Çavuş, ${ }^{2}$ (D) Mesut Bakır, ${ }^{3}$ () Duygu Yılmaz,, \\ (i) Sinan Yıldırım ${ }^{5}$ \\ 'Department of Emergency Medicine, Mersin City Training and Research Hospital, Mersin, Turkey \\ ${ }^{2}$ Department of Emergency Medicine, Ankara Training and Research Hospital, Ankara, Turkey \\ ${ }^{3}$ Department of Anesthesiology, Division of Algology, Mersin University Faculty of Medicine, Mersin, Turkey \\ ${ }^{4}$ Department of Emergency Medicine, Manisa Turgutlu State Hospital, Manisa, Turkey \\ ${ }^{5}$ Department of Emergency Medicine, Canakkale State Hospital, Canakkale, Turkey
}

\section{ABSTRACT}

Objectives: Warfarin is an anticoagulant that is used in case of thromboembolism risk or events as a prophylactic or therapeutic agent. In this study, we investigated the emergency visits due to the bleeding complication of warfarin.

Methods: The patients admitted to emergency department with bleeding and using warfarin were included this study in a three year period. Age, gender, liver and kidney function tests, the time period of the warfarin use and the frequency of the control visits were recoded.

Results: The patients admitted to emergency department with bleeding and using warfarin were included this study in a three year period $(n=243)$. The regular follow up of coagulation parameter was observed in 92 (42.8\%) patients. One hundred six (43.6\%) of the patients had had a bleeding complication before. The most frequently observed bleeding region was urinary system $(n=87,35.8 \%)$. The INR level was greater than five in $223(91.8 \%)$ of the patients. Fresh frozen plasma was used 193 (75.3\%); prothrombin complex concentration was used in $15(6.2 \%)$ patients; conservative management was preferred in $45(18.5 \%)$ patients. Mortality rate was $22(9.1 \%)$ and 97 (39.9\%) of the patients were discharged from emergency department without hospitalization. Female gender, low hemoglobin level, abnormal liver and kidney tests, INR level over 10 and irregular INR follow up were associated with both mortality and major bleeding (respectively; $p=0.750, p<0.001$, $\mathrm{p}<0.001, \mathrm{p}<0.001, \mathrm{p}<0.001, \mathrm{p}<0.001)$.

Address for correspondence: Dr. Bahar Gülcay Çat. Department of Emergency Medicine, Mersin City Training and Research Hospital, Mersin, Turkey

Phone: +90536871 1284

E-mail: baharcat@gmail.com

Received Date: 09.05.2019

Accepted Date: 28.06.2019

Published online: 01.04 .2020

(C) Copyright 2020 by Anatolian Journal of Family Medicine -

Available online at Www.anatoljfm.org

OPEN ACCESS

Conclusion: The interaction with other medications or foods, bleeding complications, its requirement of regular follow up of coagulation parameters and dose adjustment make difficult its use. We should tell the patients the importance of following the INR level regularly, especially in patients with co-morbid diseases.

Keywords: Anticoagulant, mortality, warfarin

\section{INTRODUCTION}

Oral anticoagulants are used in prophylaxis and treatment of the patients having the risk or with current thromboembolism. Warfarin is frequently used as an oral anticoagulant agent. ${ }^{[1,2]}$ The major limitation of warfarin is the interaction with other medications or foods. Also, it requires close follow-up to avoid complications. ${ }^{[3]}$

The most frequently observed complication of warfarin usage is bleeding, which can be observed in intracranial, intra-abdominal, skin, gastrointestinal and urogenital systems. In case 
of bleeding according to the level of international normalized ratio (INR) and the bleeding region, the treatment approaches may change. The treatment options are as follows: conservative follow-up with only dose adjustment, the most frequently used method is fresh frozen plasma (FFP), other options are vitamin $\mathrm{K}$ and prothrombin complex concentrate (PCC), recombinant factor Vlla (rFVlla), tranexamic acid, thrombocyte and erythroid suspension. ${ }^{[4]}$ FFP combination with rFVIla or PCC can be preferred for major bleeding, but the thrombosis risk is high. ${ }^{[5]}$

In this study, we retrospectively investigated the warfarin using patients admitted to the emergency department with bleeding complication.

\section{METHOD}

This study is performed at the Department of Emergency Medicine, Diskapi Yildirim Beyazit Education and Research Hospital, Ankara, Turkey. This study is designed as a crosssectional study in a tertiary education and research hospital with annual emergency visits of nearly 300.000 patients. This study was conducted according to the principles of the Helsinki Declaration. After the ethics committee and institutional review board approval the patients admitted to the emergency department with bleeding and using warfarin were included in this study in a three-year period. Informed consent was signed by the patients who accepted to be included this study. Patients with trauma were excluded from this study. Age, gender, liver and kidney function tests, the time period of the warfarin use and the frequency of the control visits were recoded.

The bleeding pattern was divided as minor or major bleeding. Hematuria, gastrointestinal, intra-abdominal, intracranial bleeding, any bleeding that requires hospitalization and surgical treatment, the bleeding that caused two-unit decrease in the hemoglobin level, and the patients that were given more than two unit blood product are accepted as major bleeding.

Statistical analyses were performed using the SPSS for Windows 17.0 package program. Continuous variables were expressed as mean \pm standard deviation if they were normally distributed; categorical data were expressed as $\mathrm{n}(\%)$. The difference between categorical data was calculated by the Chi-Square test. All calculations are made two-tiled; $p<0.05$ was accepted as significant.

\section{RESULTS}

Two hundred forty-three patients were included this study. Mean age was $67.7 \% \pm 15.1$ years and $135(55.6 \%)$ of the pa- tients was male. The most frequently used dose regimen was $5 \mathrm{mg}$ a day $(n=163,67.0 \%)$. Atrial fibrillation $(n=66$, $27.2 \%$ ), cerebrovascular diseases ( $n=66,27.2 \%$ ), pulmonary thromboembolism $(n=62,25.5 \%)$ and cardiac valve diseases $(n=49,20.2 \%)$ were the reasons of warfarin treatment. One hundred thirty-nine (57.2\%) patients were following the INR level regularly. The recurrent bleeding complication was present in 106 (43.6\%) of the patients. The bleeding complication was observed in the first year of the treatment in 23 (9.4\%), 152 (62.6\%) was between 1-5 years, after five years, and the bleeding frequency was $68(28.0 \%)$. The bleeding complication was more frequently observed in patients going to control for dose adjustment longer than one year period 144 (59.2\%). The INR level was greater than 5 in $223(91.8 \%)$ of the patients.

FFP and PCC treatment was used in 193 (75.3\%) and 15 (6.2\%) patients respectively. The conservative approach in which we only advise to skip the dose one or two times and go to control examination was applied in 45 (18.5\%) patients. In 87 (35.0\%) of the patients, additional erythroid suspension was given. The frequencies of the bleeding region are shown in Figure 1.

The mortality rate was $22(9.1 \%)$. The frequency of the patients that were discharged from the emergency department was 97 (39.9\%). The possible factors that can be associated with mortality and major bleeding are shown in Table 1. The female gender, low hemoglobin level, abnormal liver and kidney functions, INR level over 10 and irregular INR follow up were associated with both mortality and major bleeding. Mortality was mostly observed due to intracranial bleeding 11 (28.9\%). The mortality rate of intracranial bleeding was 11 (33.3\%) the mortality rate in gastrointestinal bleeding was $4(22.2 \%)$; in the intra-abdominal bleeding, the rate was 6 (9.7\%) (Figure 2).

\section{DISCUSSION}

The complication risk in warfarin usage changes according to the patient, age, comorbid diseases and other medi-

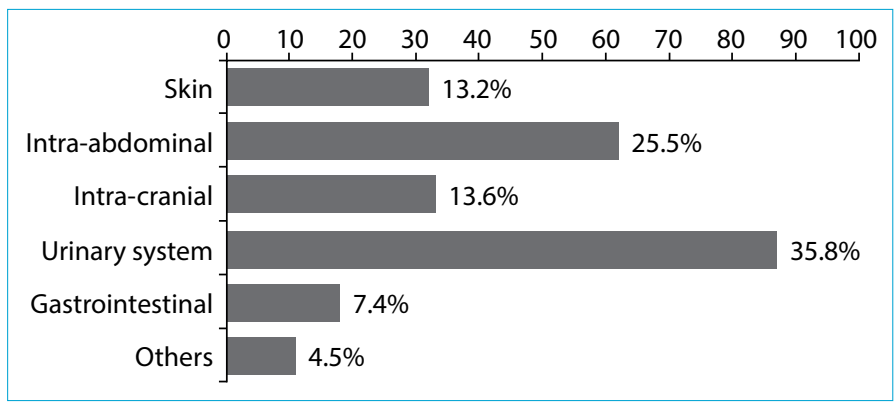

Figure 1. The frequencies of the bleeding region. 
Table 1. The relationship of mortality with gender and laboratory

\begin{tabular}{|c|c|c|c|c|c|c|}
\hline & \multicolumn{2}{|c|}{ Mortality, n (\%) } & $\mathbf{p}^{*}$ & \multicolumn{2}{|c|}{ Bleeding, n (\%) } & $\mathbf{p}^{*}$ \\
\hline Female & 15 (13.9) & $93(86.1)$ & & $59(54.6)$ & 49 (45.4) & \\
\hline Male & $7(5.2)$ & $128(94.8)$ & & $71(52.6)$ & $64(47.4)$ & \\
\hline Low hemoglobin & & & $<0.001$ & & & $<0.001$ \\
\hline Absent & $1(0.8)$ & $124(99.2)$ & & $98(78.4)$ & 27 (21.6) & \\
\hline Liver enzymes & & & $<0.001$ & & & $<0.001$ \\
\hline Abnormal & $12(42.9)$ & $16(57.1)$ & & $7(25.0)$ & $21(75.0)$ & \\
\hline Normal & $10(4.7)$ & $205(95.3)$ & & $123(57.2)$ & $92(42.8)$ & \\
\hline INR level & & & $<0.001$ & & & $<0.001$ \\
\hline$<5$ & $2(10.0)$ & $18(90.0)$ & & $14(70.0)$ & $6(30.0)$ & \\
\hline $5-10$ & $1(0.9)$ & $111(99.1)$ & & $81(72.3)$ & $31(27.7)$ & \\
\hline$>10$ & $19(17.1)$ & $92(82.9)$ & & $35(31.5)$ & 76 (68.5) & \\
\hline INR follow up & & & 0.010 & & & $<0.001$ \\
\hline Regular & $7(5.0)$ & $132(95.0)$ & & $86(61.9)$ & $53(38.1)$ & \\
\hline Irregular & $15(14.4)$ & 89 (85.6) & & $44(42.3)$ & $60(57.7)$ & \\
\hline
\end{tabular}

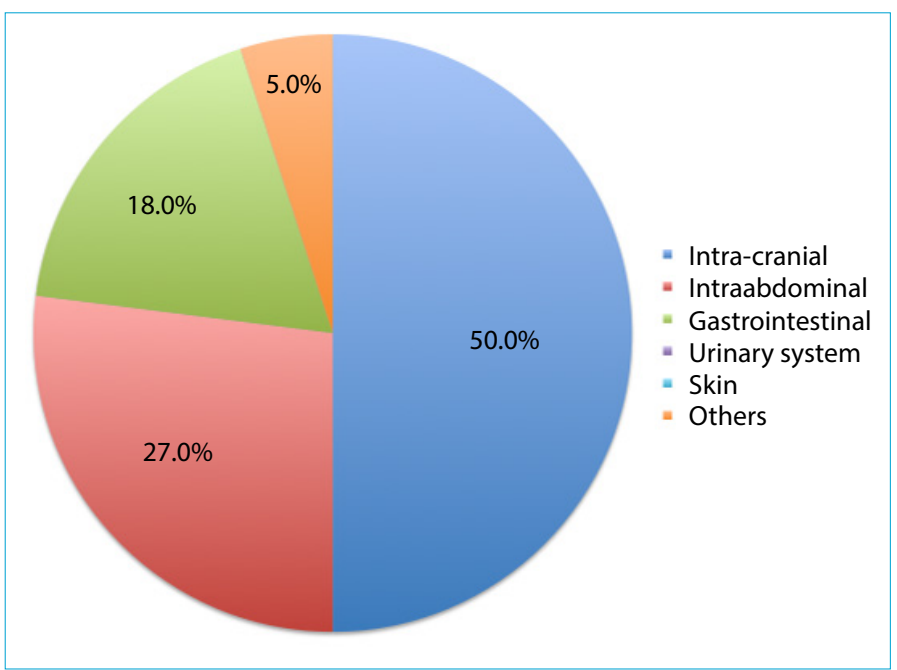

Figure 2. The mortality rates in bleeding region.

cations that patients using. We can observe the bleeding complications in every age but over 50 years, the frequency increases. ${ }^{[6,7]}$ It was similar, and the mean age was 67.7 years in our study. It is reported previously that the bleeding complications increases in the elderly. Also, the bleeding types that frequently end with mortality are observed in this age group. ${ }^{[8-10]}$
In our study, male and female patient frequencies were similar, and the mortality rate was similar in males and females. However, some of the studies reported the bleeding complications were more frequent in females. ${ }^{[11]}$

The bleeding complication of warfarin overdose was frequently observed in patients with co-morbid diseases and other medications. Also, gastrointestinal system and syncope were reported frequently over 65 years of age. ${ }^{[12]}$ Warfarin is used for thromboembolic events or prophylaxis for thromboembolism. In the literature, the frequency changes according to studies, but generally, atrial fibrillation is the most frequent cause of warfarin usage..$^{[6]}$ In our study, the most frequent cause was cerebrovascular diseases, atrial fibrillation, cardiac valvular diseases and pulmonary thromboembolism with similar percentages.

The bleeding due to warfarin was mostly observed in the gastrointestinal system, but skin hematomas, hemoptysis, intra-abdominal hematoma, hematuria, vaginal bleeding, gingival bleeding and intracranial hematoma are the other causes. ${ }^{[13]}$ In our study, we observed bleeding mostly in the urinary system following with intra-abdominal hematoma. Skin necrosis is a rare complication which is observed 0.1- 
$1 \%$ of the warfarin users and frequently observed in the first week. ${ }^{[14,15]}$

In our study, the female gender, low hemoglobin level, abnormal liver and kidney functions, INR level over 10 and irregular INR follow up were associated with both mortality and major bleeding. The warfarin usage education in anticoagulation clinics or units decreases the complications and increases patient compliance. ${ }^{[16]}$ Additionally, some studies reported that home type coagulometer and self monitorization were as successful as anticoagulation clinics. ${ }^{[17,18]}$

The treatment options are conservative follow-up with only dose adjustment. The most frequently used methods are FFP, vitamin K, PCC, rFVIla, tranexamic acid, thrombocyte and erythroid suspension. ${ }^{[19]}$ In our study, dose adjustment was enough in $18.5 \%$ of the patients. Garcia et al. reported that in case of warfarin overdose, conservative treatment was applied in $50 \%$ of the patients and vitamin $\mathrm{K}$ was applied for $8.7 \%$ of the patients. ${ }^{[20]}$

The INR level equal and over six increases the bleeding risk. ${ }^{[21,22]}$ In the literature, a high INR level is related to major bleeding complication and also mortality. ${ }^{[21,22]}$ The regular and strict INR follow up reduces bleeding complications. ${ }^{[16]}$ Consistent with the literature, our study revealed that the INR level over five and irregular INR follow up increases the major bleeding and mortality.

We could not obtain the data about the regular diets of the patients that may increase or decrease the consumption of warfarin.

\section{CONCLUSION}

Female gender, low hemoglobin level, abnormal liver and kidney tests, INR level over 10, irregular INR follow up are associated with both mortality and major bleeding. We should tell the patients the importance of following the INR level regularly, especially in patients with co-morbid diseases.

\section{Disclosures}

Peer-review: Externally peer-reviewed.

Conflict of Interest: None declared.

Ethics Committee Approval: The Ethics Committee of Ankara Dışkapı Yıldırım Beyazıt Education and Research Hospital provided the ethics committee approval for this study (25.03.2013-08/18).

Authorship Contributions: Concept - B.G.Ç., U.Y.Ç., M.B.; Design B.G.Ç., D.Y., S.Y.; Supervision - U.Y.Ç., S.Y.; Materials - B.G.Ç., M.B., D.Y.; Data collection \&/or processing - B.G.Ç., M.B., D.Y.; Analysis and/or interpretation - B.G.Ç., U.Y.Ç., D.Y.; Literature search - B.G.Ç., M.B., S.Y.; Writing - B.G.Ç., U.Y.Ç., M.B.; Critical review - B.G.Ç., U.Y.Ç., S.Y.

\section{REFERENCES}

1. Czuprynska J, Patel JP, Arya R. Current challenges and future prospects in oral anticoagulant therapy. $\mathrm{Br} J$ Haematol 2017;178(6):838-51. [CrossRef]

2. Harel Z, Chertow GM, Shah PS, Harel S, Dorian P, Yan AT, et al. Warfarin and the Risk of Stroke and Bleeding in Patients With Atrial Fibrillation Receiving Dialysis: A Systematic Review and Meta-analysis. Can J Cardiol 2017;33(6):737-46. [CrossRef]

3. Massaro AR, Lip GYH. Stroke Prevention in Atrial Fibrillation: Focus on Latin America. Arq Bras Cardiol 2016;107:576-89.

4. Meltzer J, Guenzer JR. Anticoagulant Reversal and Anesthetic Considerations. Anesthesiol Clin 2017;35(2):191-205.

5. DeLoughery E, Avery B, DeLoughery TG. Retrospective study of rFVIla, 4-factor PCC, and a rFVIIa and 3-factor PCC combination in improving bleeding outcomes in the warfarin and non-warfarin patient. Am J Hematol 2016;91(7):705-8.

6. Fanikos J, Grasso-Correnti N, Shah R, Kucher N, Goldhaber SZ. Major bleeding complications in a specialized anticoagulation service. Am J Cardiol 2005;96(4):595-8. [CrossRef]

7. Baydın A, Nargıs C, Karataş D, Güven H, Doğanay Z, Yardan T. Retrospective evaluation of patients used warfarin admitted to emergency department. Turk J Emerg Med 2006;6:56-9.

8. Rivera-Caravaca JM, Roldán V, Esteve-Pastor MA, Valdés M, Vicente V, Lip GYH, et al. Cessation of oral anticoagulation is an important risk factor for stroke and mortality in atrial fibrillation patients. Thromb Haemost 2017;117(7):1448-54. [CrossRef]

9. Melkonian M, Jarzebowski W, Pautas E, Siguret V, Belmin J, Lafuente-Lafuente $C$. Bleeding risk of antiplatelet drugs compared with oral anticoagulants in older patients with atrial fibrillation: a systematic review and meta-analysis. J Thromb Haemost 2017;15(7):1500-10. [CrossRef]

10. Palareti G, Antonucci E, Migliaccio L, Erba N, Marongiu F, Pengo $\mathrm{V}$, et al. Vitamin $\mathrm{K}$ antagonist therapy: changes in the treated populations and in management results in Italian anticoagulation clinics compared with those recorded 20 years ago. Intern Emerg Med 2017;12(8):1109-19. [CrossRef]

11. Gomberg-Maitland M, Wenger NK, Feyzi J, Lengyel M, Volgman AS, Petersen $P$, et al. Anticoagulation in women with non-valvular atrial fibrillation in the stroke prevention using an oral thrombin inhibitor (SPORTIF) trials. Eur Heart J 2006;27(16):1947-53. [CrossRef]

12. Beyth RJ, Quinn LM, Landefeld CS. Prospective evaluation of an index for predicting the risk of major bleeding in outpatients treated with warfarin. Am J Med 1998;105(2):91-9.

13. Shimomura A, Nagata N, Shimbo T, Sakurai T, Moriyasu S, Okubo $\mathrm{H}$, et al. A New Predictive Model for Acute Gastrointestinal Bleeding in Patients Taking Oral Anticoagulants: A Cohort Study. J Gastroenterol Hepatol 2018;33(1):164-71. [CrossRef] 14. Sahu KK, Varma SC. Warfarin induced skin necrosis. Indian J Med Res 2016;143(4):528-9. [CrossRef]

15. Karimi K, Odhav A, Kollipara R, Fike J, Stanford C, Hall JC. Acute 
Cutaneous Necrosis: A Guide to Early Diagnosis and Treatment. J Cutan Med Surg 2017;21(5):425-37. [CrossRef]

16. Raparelli V, Proietti M, Cangemi R, Lip GY, Lane DA, Basili S. Adherence to oral anticoagulant therapy in patients with atrial fibrillation. Thromb Haemost 2017;117(2):209-18. [CrossRef]

17. Ward A, Tompson A, Fitzmaurice D, Sutton S, Perera R, Heneghan C. Cohort study of Anticoagulation Self-Monitoring (CASM): a prospective study of its effectiveness in the community. Br J Gen Pract 2015;65(636):e428-37. [CrossRef]

18. Heneghan CJ, Spencer EA, Mahtani KR. Cochrane corner: selfmonitoring and self-management of oral anticoagulation. Heart 2017;103(12):895-6. [CrossRef]

19. Ansell J, Hirsh J, Poller L, Bussey H, Jacobson A, Hylek E. The pharmacology and management of the vitamin $\mathrm{K}$ antago- nists: the Seventh ACCP Conference on Antithrombotic and Thrombolytic Therapy. Chest 2004;126(3 Suppl):204S-33S.

20. Garcia DA, Regan S, Crowther M, Hylek EM. The risk of hemorrhage among patients with warfarin-associated coagulopathy. J Am Coll Cardiol 2006;47(4):804-8. [CrossRef]

21. Visser LE, Bleumink GS, Trienekens PH, Vulto AG, Hofman A, Stricker $\mathrm{BH}$. The risk of overanticoagulation in patients with heart failure on coumarin anticoagulants. $\mathrm{Br} J$ Haematol 2004;127(1):85-9. [CrossRef]

22. Hylek EM, Chang YC, Skates SJ, Hughes RA, Singer DE. Prospective study of the outcomes of ambulatory patients with excessive warfarin anticoagulation. Arch Intern Med 2000;160(11):1612-7. [CrossRef] 